\title{
Lidar Observations of Sporadic Fe and Na Layers in the Mesopause Region over Equator
}

\author{
Yasukuni SHIBATA, Chikao NAGASAWA, Makoto ABO \\ Faculty of System Design, Tokyo Metropolitan University, Hachioji, Japan \\ Takashi MARUYAMA, Susumu SAITO \\ National Institute of Information and Communications Technology (NICT), Tokyo, Japan \\ and \\ Takuji NAKAMURA \\ Research Institute for Sustainable Humanosphere (RISH), Kyoto University, Uji, Japan \\ (Manuscript received 19 November 2005, in final form 11 April 2006)
}

\begin{abstract}
Characteristics of sodium and iron layers in the mesopause region over the equator observed with the resonance scattering lidars installed at Kototabang, Indonesia $\left(0.2^{\circ} \mathrm{S}, 100.3^{\circ} \mathrm{E}\right)$ are reported. These lidars were operated during the night. The sporadic sodium layer (Nas) and the sporadic iron layer (Fes) were detected in almost every observing opportunity other latitude regions. Nas and Fes layers appeared almost at the same time and the heights above $90 \mathrm{~km}$. However, Fes layers appeared below $90 \mathrm{~km}$ as well. The occurrence of the Nas layer correlated well with that of sporadic E layer which was observed simultaneously by the ionosonde at Kototabang. On the other hand, the occurrences of the Nas and Fes layers does not correlate with that of the wind shear which has been observed simultaneously by the meteor radar at Kototabang. This result is not in agreement with the result of simultaneous observations by the $\mathrm{Na}$ lidar and the MU radar at Hachioji $\left(35.6^{\circ} \mathrm{N}\right)$ and Shigaraki $\left(34.9^{\circ} \mathrm{N}\right)$ in mid-latitude.
\end{abstract}

\section{Introduction}

The resonance scattering lidar is used for observing metal atomic layers such as sodium, iron and potassium that exist around the mesopause region between 80 and $100 \mathrm{~km}$. Since the resonance scattering cross section is very large compared with the cross section of Rayleigh scattering or Raman scattering, the resonance

Corresponding author: Yasukuni Shibata, Faculty of System Design, Tokyo Metropolitan University, 1-1, Minami-Ohsawa, Hachioji 192-0397, Japan. E-mail: shibata@eei.metro-u.ac.jp

(C) 2006, Meteorological Society of Japan scattering lidar is able to detect a small amount matter. Metal atomic layers in the mesosphere are an excellent tracer of the atmospheric wave motion in the region between 80 and $100 \mathrm{~km}$. Resonance scattering is observed when laser wavelength is tuned to the resonance-line wavelength of a molecule or an atom.

The existence of the layer of sodium atoms in the mesopause region had already been deduced from twilight observations (Chamberlain et al. 1958). The first resonance scattering lidar observation of the $\mathrm{Na}$ layer was made by Bowman et al. (1969). Gardner et al. observed wave-like structures that were interpreted as 
gravity waves and also observed the horizontal structure of the $\mathrm{Na}$ layer in equatorial and polar areas with an airborne $\mathrm{Na}$ lidar (Gardner et al. 1987). In the Southern hemisphere, longterm observations of the Na layer for over 15 years were made by Clemesha et al. (1992). On the other hand, in the Northern mid-latitude, Nagasawa and Abo (1995) also have made long-term observations of the Na layer for over 10 years. Moreover, in addition to sodium, observations of the metallic species such as iron, potassium, lithium, calcium in atomic and ionic form $\left(\mathrm{Fe}, \mathrm{K}, \mathrm{Li}, \mathrm{Ca}, \mathrm{Ca}^{+}\right)$were successfully observed.

During these observations, a sudden formation of a thin sodium layer, superposed in the background mesospheric sodium layers was discovered and this enhanced layer is called the sporadic sodium layer (Nas). Usually, Nas has a thin layer with a width of 1-2 km, lasting for a few tens of minutes to several hours, and the ratio of peak $\mathrm{Na}$ density to the normal density is usually from three to five, occasionally, as large as ten (Nagasawa and Abo 1995). The appearance of such a sudden thin layer is also reported also in other metallic atoms, such as Fe and K (Bills R.E. and C.S. Gardner 1990; Hoffner J. et al. 1999).

The observation of Nas at Sao Paulo, Brazil $\left(23^{\circ} \mathrm{S}\right)$ was the first report of Nas event (Clemesha et al. 1978). Many Nas events were observed in the $1980 \mathrm{~s}$ in Norway $\left(69^{\circ} \mathrm{N}\right.$ ) (von Zahn et al. 1987; von Zahn and Hansen 1988), and Longyearbyen, Svalbard $\left(78^{\circ} \mathrm{N}\right)$ (Gardner et al. 1988), Tokyo $\left(35^{\circ} \mathrm{N}\right)$ (Nagasawa et al. 1995), Mauna Kea, Hawaii $\left(20^{\circ} \mathrm{N}\right)$ (Kwon et al. $1988)$ and Arecibo, Puerto Rico $\left(18^{\circ} \mathrm{N}\right)$ (Beatty et al. 1989). Thus, Nas has been observed between low latitudes and high latitudes. In the high latitude observations, a strong correlations between Nas and sporadic E (Es) in the ionosphere occurrence has been observed and it is suggested that a neutral sodium atom is made from sodium ion (von Zahn et al. 1987; von Zahn and Hansen 1988). It is noteworthy that the correlation between Nas and Es, based on the observations at Hachioji at mid-latitude was also reported (Nagasawa and Abo 1995). It is also suggested that a temperature increase due to tides or gravity wave may cause the increase of the sodium density, since the sodium abundance is sensitive to temperature (Zhou et al. 1993). Production of sodium atom from $\mathrm{NaHCO}_{3}$ of the meteor origin has been discussed (Plane, J.M.C. et al. 1998). Moreover, in the mid-latitude, correlation of Nas with the wind shear in the mesopause area is also reported (Miyagawa et al. 1999).

Although regular observations of metal atomic layers such as sodium and iron have been performed between the mid-latitude and the polar regions, there is almost no example of observations in the equatorial area. In order to study the atmospheric structure in the mesopause region over the equatorial zone, we installed a $\mathrm{Na}$ lidar in Bandung, Indonesia $\left(7^{\circ} \mathrm{S}\right.$, $107^{\circ} \mathrm{E}$ ) in 2002 , and made the test observation of $\mathrm{Na}$ layer. This $\mathrm{Na}$ lidar was then moved to Kototabang, Indonesia $\left(0.2^{\circ} \mathrm{S}, 100.3^{\circ} \mathrm{E}\right)$ in 2004 . Simultaneous observations of sodium density and iron density with a $\mathrm{Fe}$ resonance scattering lidar were performed in the equatorial area. In this paper, correlation of these lidar data and the sporadic $\mathrm{E}$ layer with an ionosonde at the same location is described. Moreover, the Nas observed at Hachioji, Japan $\left(35.6^{\circ} \mathrm{N}, 139.4^{\circ} \mathrm{E}\right)$ and the wind shear observed at Shigaraki, Japan $\left(34.9^{\circ} \mathrm{N}, 136.1^{\circ} \mathrm{E}\right)$ is compared with that observed at Kototabang, Indonesia.

\section{Instrumentation}

A block diagram of the lidar system for the mesosphere metal atomic-layer observation, installed in Kototabang is shown in Fig. 1 and specifications of the lidar system are listed in Table 1. The Na resonance scattering lidar consists of a tunable dye laser pumped by a frequency doubled Nd:YAG laser. The Fe resonance scattering lidar consists of a frequency doubled Ti:Sapphire laser pumped by another frequency doubled $\mathrm{Nd}$ :YAG laser. In order to observe some metal atomic layers, such as $\mathrm{K}(770 \mathrm{~nm}), \mathrm{Fe}(372 \mathrm{~nm}, 374 \mathrm{~nm})$, and $\mathrm{Ca}^{+}$ $(393 \mathrm{~nm})$, the Ti:sapphire laser, which is a variable wavelength laser, was selected. The wavelength of dye laser is tuned to the $\mathrm{Na}$ resonance wavelength $(589 \mathrm{~nm})$ so that the filter transmission intensity of the laser beam may become the maximum using a $\mathrm{Na}$ Faraday filter. The wavelength of the Ti:Sapphire laser is tuned to the $\mathrm{Fe}$ resonance wavelength $(372 \mathrm{~nm})$ using the wavemeter with $0.1 \mathrm{pm}$ resolution. The receiving system consists of three telescopes each $45 \mathrm{~cm}$ diameter. The one with the photomulti- 


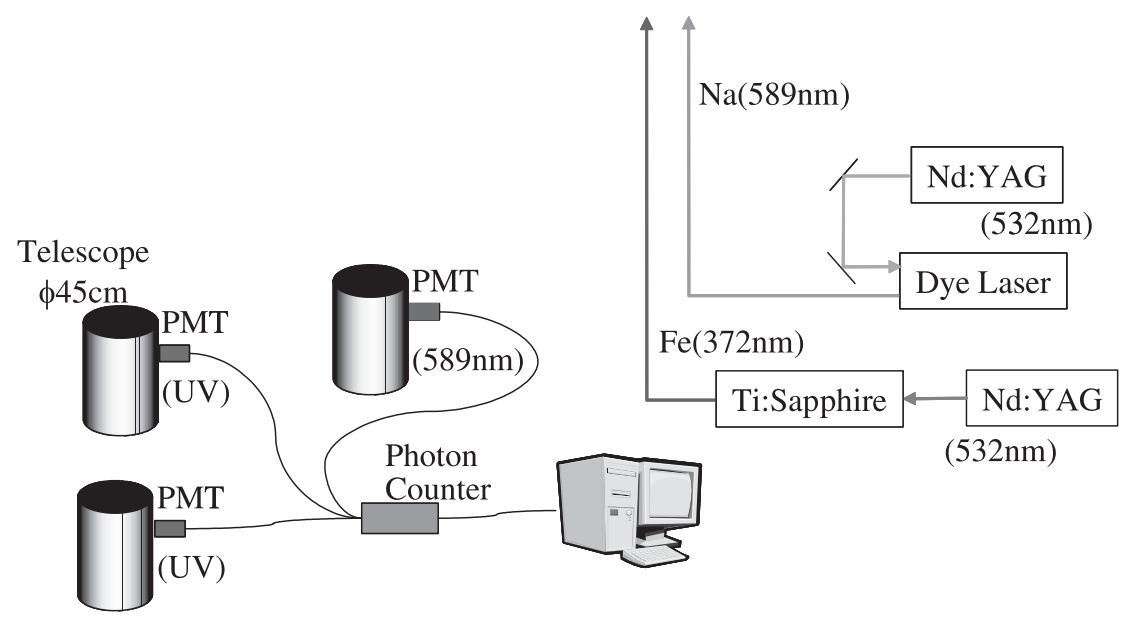

Fig. 1. The block diagram of the lidar system for the observation of the mesosphere metallic atom layer installed in Kototabang.

plier tube (PMT) which attached a $589 \mathrm{~nm}$ interference filter is only for Na observation. The other two with the cut-off filter that cuts the wavelength more than $400 \mathrm{~nm}$ are only for ultraviolet wavelengths.

EAR (Equatorial Atmosphere Radar) is a large Doppler radar for atmospheric observation at the equator. It was build in March 2001, in collaboration with the Research Institute for

Table 1. Parameters of the resonance lidar system.

\begin{tabular}{|l|c|c|}
\hline & Dye laser & $\begin{array}{c}\text { Ti:Sapphire } \\
\text { laser }\end{array}$ \\
\hline Wavelength & $589 \mathrm{~nm}$ & $\begin{array}{l}372 \mathrm{~nm}, \\
374 \mathrm{~nm}\end{array}$ \\
\hline $\begin{array}{l}\text { Pulse } \\
\text { energy }\end{array}$ & $30 \mathrm{~mJ}$ & $13 \mathrm{~mJ}$ \\
\hline $\begin{array}{l}\text { Laser } \\
\text { linewidth }\end{array}$ & $20 \mathrm{pm}$ & $3 \mathrm{pm}$ \\
\hline $\begin{array}{l}\text { Laser } \\
\text { wavelength } \\
\text { stability }\end{array}$ & $0.5 \mathrm{pm}$ & $0.5 \mathrm{pm}$ \\
\hline $\begin{array}{l}\text { Repetition } \\
\text { rate }\end{array}$ & $10 \mathrm{~Hz}$ & $10 \mathrm{~Hz}$ \\
\hline $\begin{array}{l}\text { Range } \\
\text { resolution }\end{array}$ & $150 \mathrm{~m}(\mathrm{Min})$. & $150 \mathrm{~m}(\mathrm{Min})$. \\
\hline $\begin{array}{l}\text { Telescope } \\
\text { diameter }\end{array}$ & $45 \mathrm{~cm} \times 1$ & $45 \mathrm{~cm} \times 2$ \\
\hline
\end{tabular}

Sustainable Humanosphere (RISH), Kyoto University and the National institute of Aeronautics and Space of Indonesia (LAPAN). The EAR has a circular antenna array of about $110 \mathrm{~m}$ diameter, which consists of 560 three-element Yagis. The EAR transmits $47 \mathrm{MHz}$ radio wave to the sky, and receives echoes scattered back by atmospheric turbulence. The EAR can observe winds and turbulence in the altitude range from $1.5 \mathrm{~km}$ to $20 \mathrm{~km}$ and can also observe echoes from ionospheric irregularities at heights more than $90 \mathrm{~km}$ (Fukao et al. 2003). The meteor radar is a radio interferometer and has a three-element Yagi transmitting antenna and five two-element Yagi receiving antenna. It has an effective time and height resolution of $2 \mathrm{~km} \times 1$ hour from $80 \mathrm{~km}$ to $102-3 \mathrm{~km}$ altitude. The meteor radar obtains zonal and meridional winds. The wind shear is calculated by taking the difference between zonal or meridional wind velocities of two neighboring heights in the profile. The total wind shear $d V / d z$ is

$$
d V / d z=\sqrt{(d u / d z)^{2}+(d v / d z)^{2}}
$$

where $d u / d z$ is the zonal wind shear, $d v / d z$ is the meridional wind shear.

\section{Observations}

The numbers of $\mathrm{Na}$ layer observations and $\mathrm{Fe}$ layer observations at Kototabang are summarized in Table 2. Observations of the Na layer have been carried out since August 2004, and 
Table 2. The numbers of lidar observations and Es observations at Kototabang.

\begin{tabular}{|l|c|c|c|}
\hline \multirow{2}{*}{ Date } & \multicolumn{3}{|c|}{ Observation } \\
\cline { 2 - 4 } & $\mathrm{Na}(\mathrm{LST})$ & $\mathrm{Fe}(\mathrm{LST})$ & Es \\
\hline \hline 24-25 June 2005 & $22: 33-03: 03$ & $19: 18-03: 03$ & Appearance \\
\hline 30 July 2005 & $01: 12-05: 32$ & $01: 12-05: 32$ & Appearance \\
\hline 1-2 August 2005 & & $20: 35-02: 35$ & Appearance \\
\hline 2-3 August 2005 & $22: 53-05: 29$ & $20: 37-05: 29$ & Appearance \\
\hline 3-4 August 2005 & $20: 21-05: 18$ & $20: 21-05: 18$ & Appearance \\
\hline 4-5 August 2005 & & $21: 40-05: 40$ & Appearance \\
\hline 27-28 August 2005 & $20: 12-05: 22$ & $20: 12-05: 22$ & Appearance \\
\hline 28-29 August 2005 & $20: 01-05: 30$ & $20: 01-05: 30$ & Appearance \\
\hline
\end{tabular}

observations of the Fe layer have been carried out since June 2005. Six simultaneous observations of the $\mathrm{Na}$ layer and the $\mathrm{Fe}$ layer were performed until August 2005. Na layer and Fe layer which were observed by Kototabang are compared. Moreover, ionosphere sporadic $\mathrm{E}$ layer (Es) and the meteor-wind distribution were observed with an ionosonde and a meteor radar respectively, which had been installed at the same site as the lidar station. There is no direct relationship to production of the neutral atomic layer and the electron density.

Although many studies on Nas have been performed, the definition of Nas is not clear. In order to avoid this uncertainty, Nagasawa and Abo (1995) have described the objective method for choosing a Nas event. The full width of half maximum (FWHM) of the Na layer for each enhancement event is calculated, and candidates with a FWHM thickness smaller than $5 \mathrm{~km}$ are chosen. The ratio of the maximum density at the enhancement event to the normal density that is assumed without this enhancement event is calculated at the same altitude. If this ratio is greater than two, the event is judged to be a Nas event. A Fes event is defined as well as the Nas event.

Figure 2 shows the profiles of a $\mathrm{Na}$ density at Kototabang, Indonesia on 29 August 2005. During this night the background structure of the sodium layer profile did not change significantly, and downward phase propagations relevant to atmospheric waves were observed. Starting at 2:30 LST $(=\mathrm{JST}=\mathrm{UT}+7)$, a sig-

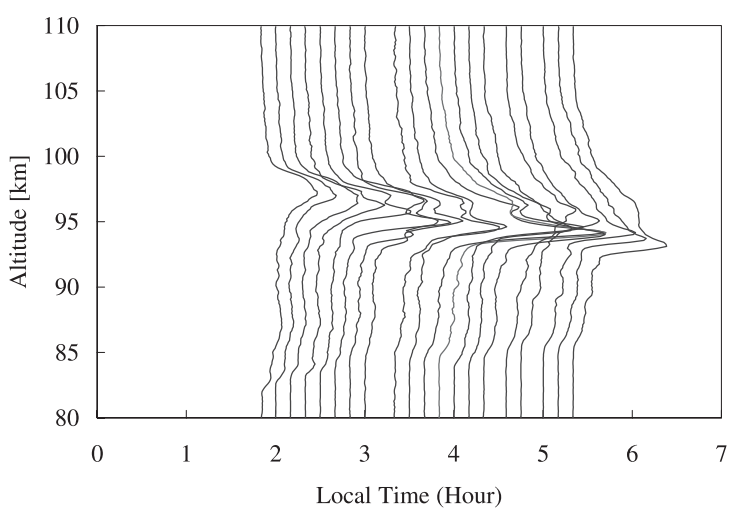

Fig. 2. An example of $\mathrm{Na}$ density profiles at Kototabang, Indonesia on 29 August 2005.

nificant Nas event appeared at $95 \mathrm{~km}$, and continued for about 2 hours, with the peak moving downward slightly at a speed of about $1.2 \mathrm{~km} /$ hour. At 3:47 LST, the peak Nas density reached a maximum at $94.3 \mathrm{~km}$, the ratio of the Nas maximum to the normal layer being 3.0.

\subsection{Lidar observations and Es observation}

In this section, we discuss the characteristic relation between lidar observations and Es observation.

\section{Case 1}

Figure 3 shows density distributions of $\mathrm{Na}$ layer and Fe layer, and the peak altitude of Es event (h'Es) with $2 \mathrm{~km}$ height resolution on 2930 July 2005 at Kototabang. Lidar observations 
were sometimes prevented by cloudy weather conditions. Starting at 1:17 LST, large Nas event appeared at $96 \mathrm{~km}$ and continued for 4 hours, with the peak moving downward slightly from 2:00 LST to 3:00 LST. On the other hand, Fes event did not appear in this night. Although the shape of both atomic layers was the same below $90 \mathrm{~km}$, that was not the same above $90 \mathrm{~km}$. Es event appeared over $110 \mathrm{~km}$ at 22:00 LST and moved downward to the Nas altitude at 1:00 LST. However, Es event was not detected after 2:00 LST.

\section{Case 2}

Figure 4 shows density distributions of $\mathrm{Na}$ layer and Fe layer, and the peak altitude of Es (h'Es) on 2-3 August 2005 at Kototabang. Na layer and Fe layer had the same shape below $90 \mathrm{~km}$. Small Nas event appeared at $95 \mathrm{~km}$ at 3:20 LST for 2 hours, with the peak moving downward slightly from $95 \mathrm{~km}$ to $94 \mathrm{~km}$. Fes event appeared at $90 \mathrm{~km}$ at 20:30 LST for about 20 minutes and also appeared at $88 \mathrm{~km}$ at 23:00 LST for an hour. There was no correlation of Nas and Fes in this night. Es event appeared at $95 \mathrm{~km}$ at 20:00 LST and over $100 \mathrm{~km}$ after 4:00 LST. Es was not detected during two lidar observations.

\section{Case 3}

Figure 5 shows density distributions of $\mathrm{Na}$ layer and $\mathrm{Fe}$ layer, and the peak altitude of Es (h'Es) on 28-29 August 2005 at Kototabang. Na layer and Fe layer had also the same shape below $90 \mathrm{~km}$. Large Nas event appeared at $95 \mathrm{~km}$ at 2:00 LST and continued until 5:00, with the peak moving downward slightly $94 \mathrm{~km}$ from 2:00 LST to 5:00 LST. Fes evnet appeared at $84 \mathrm{~km}$ at 20:00 LST and also appeared at $94 \mathrm{~km}$ at 3:00 LST for about 90 minutes. In this case, Fes is correlated well with Nas after midnight. Es event appeared over $100 \mathrm{~km}$ at 23:30 LST and suddenly appeared at 0:00 LST until dawn at $96 \mathrm{~km}$. In this case, Es was correlated well with Nas.

The characteristics of the Nas, Fes and Es events are summarized in Table 3 and altitude distributions of Nas events and Fes events at Kototabang and Nas events at Hachioji are shown in Fig. 6. We have a sodium lidar at Tokyo Metropolitan University (TMU) in Hachioji $\left(35.6^{\circ} \mathrm{N}, 139.4^{\circ} \mathrm{E}\right)$. The TMU Na lidar system consists of a tunable dye laser, pumped by a frequency doubled Nd:YAG laser, a receiving telescope, a photomultiplier tube detector, a monitoring system for the transmitted laser wavelength, and a data acquisition system. A receiving Cassegrainian telescope with a primary mirror with a diameter of $28 \mathrm{~cm}$ (-October 1992), $35 \mathrm{~cm}$ (October 1992December 1993), or $60 \mathrm{~cm}$ (December 1993-) was used. The laser pulse repetition rate was $10 \mathrm{~Hz}$, the laser linewidth is $2.5 \mathrm{pm}$ and the wavelength stability is $0.5 \mathrm{pm}$.

Although Nas events appeared at various heights between $90 \mathrm{~km}$ and above $105 \mathrm{~km}$ at Hachioji, Nas events appeared only around $95 \mathrm{~km}$ at Kototabang. The Nas event and Es event were correlated, but the Fes event and Es event were not correlated. Nas and Fes appear in the same time and height in many cases above $90 \mathrm{~km}$, however, Fes also appears below $90 \mathrm{~km}$. Several data in a limited period, make it difficult to conclude the general relationship between Nas, Fes and Es. In order to clarify these relations, we will perform these observations continuously.

\subsection{Lidar observations and wind shear observation}

It was reported that a strong wind shear of the horizontal wind is more likely to accompany the Nas occurrence by the simultaneous observations with the $\mathrm{Na}$ lidar and the MU radar at Hachioji $\left(35.6^{\circ} \mathrm{N}, 139.4^{\circ} \mathrm{E}\right)$ and Shigaraki $\left(34.9^{\circ} \mathrm{N}, 136.1^{\circ} \mathrm{E}\right)$, Japan from 1992 to 1997 (Miyagawa et al. 1999). The MU radar is a monostatic pulse Doppler radar operated at $46.5 \mathrm{MHz}$ VHF, constructed at Shigaraki, Shiga, Japan $\left(34.9^{\circ} \mathrm{N}, 136.1^{\circ} \mathrm{E}\right)$. The Shigaraki $\mathrm{Na}$ lidar was operated at the Shigaraki MU observatory in September 1995 by Shinshu University. The basic system of this lidar was the same that used by Nomura et al. (1987). A Shumidt-Cassegrainian telescope with a diameter of $35.5 \mathrm{~cm}$ was used. The laser pulse repetition rates were $0.2 \mathrm{~Hz}$ (-October 1996) and $0.5 \mathrm{~Hz}$ (October 1996-), respectively.

Based on the mesosphere wind profile with time and height resolutions of 1 hour and $2 \mathrm{~km}$ observed by the meteor radar from June 2005 to August 2005, we investigated the relation between sporadic atomic layer and wind shear over the equator. The event number of $\mathrm{Nas}$ and Fes at Kototabang and the event number of 

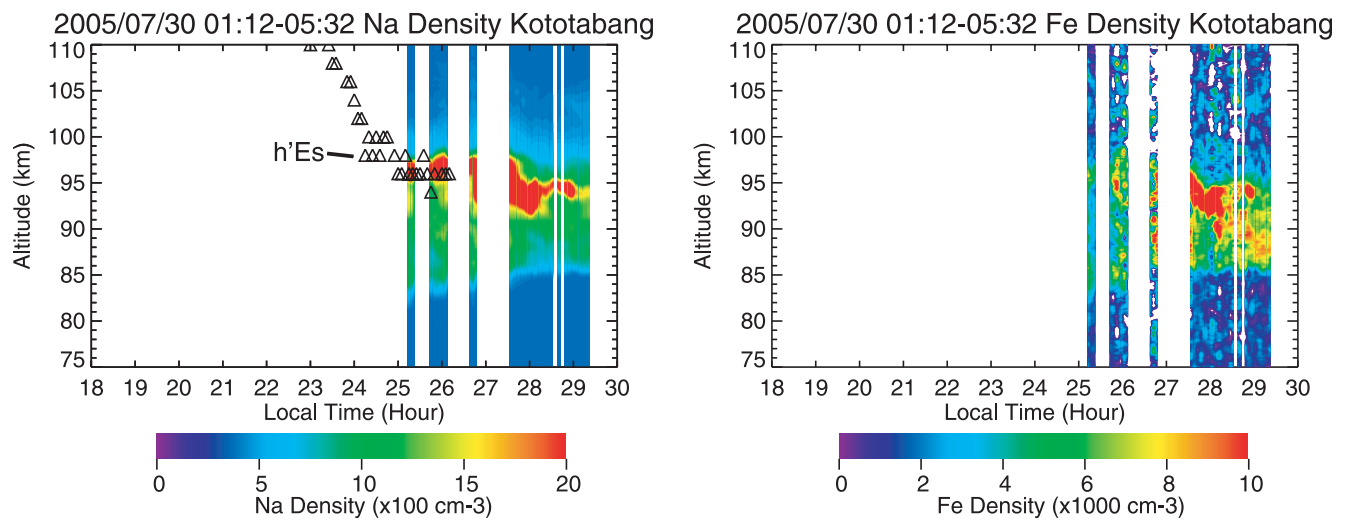

Fig. 3. Density distributions of Na layer and Fe layer, and the peak altitude of Es (h'Es) on 29-30 July 2005 at Kototabang.
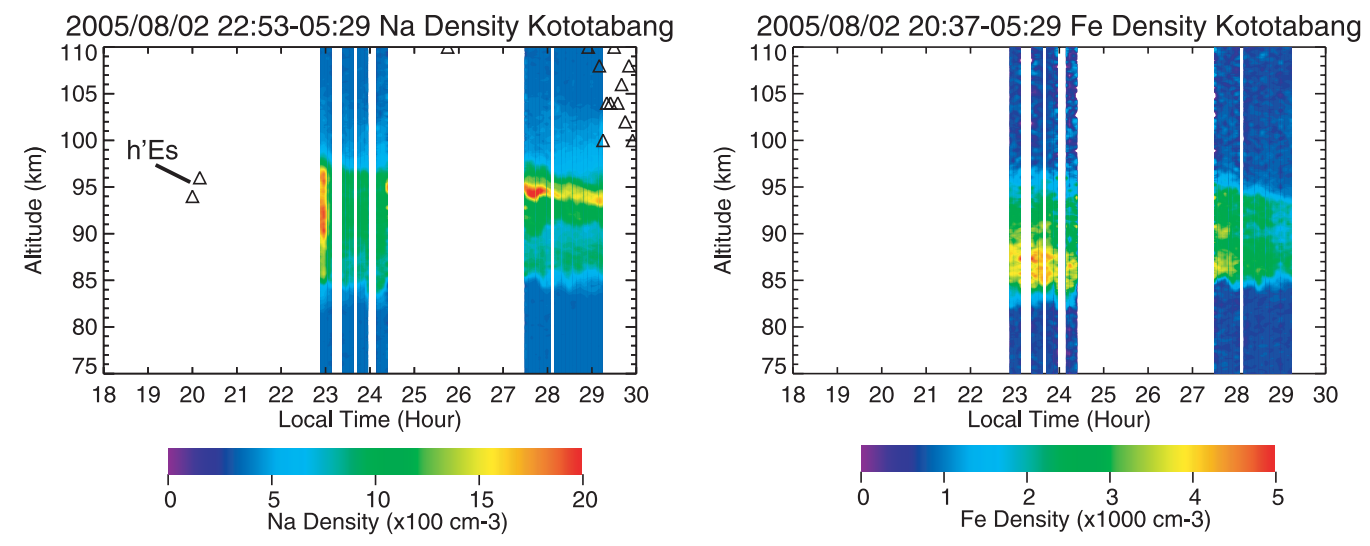

Fig. 4. Density distributions of Na layer and Fe layer, and the peak altitude of Es (h'Es) on 2-3 August 2005 at Kototabang.
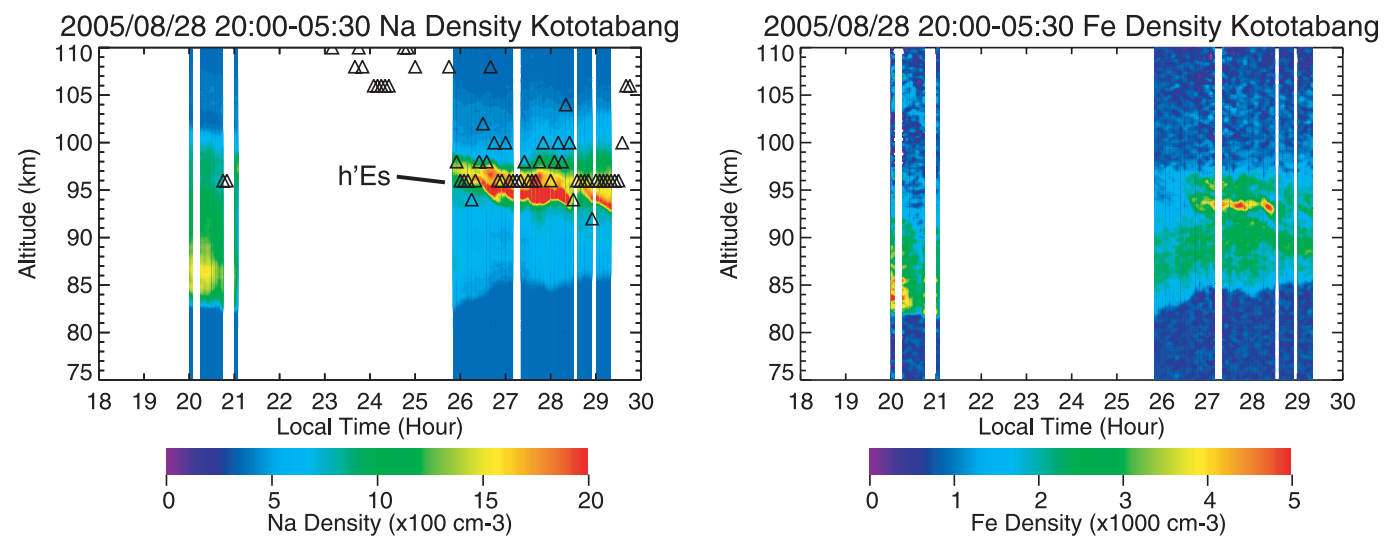

Fig. 5. Density distributions of Na layer and Fe layer, and the peak altitude of Es (h'Es) on 28-29 August 2005 at Kototabang. 
Table 3. The characteristics of the Nas, Fes and Es events.

\begin{tabular}{|c|c|c|c|c|}
\hline \multirow[b]{2}{*}{ Date } & \multicolumn{3}{|c|}{ Peak Altitude (km) } & \multirow{2}{*}{$\begin{array}{l}\text { Correlation } \\
\text { Nas and Es }\end{array}$} \\
\hline & Nas & Fes & Es & \\
\hline 24-25 June 2005 & 97 & 88 & 95 & Yes \\
\hline 29-30 July 2005 & 96 & 95 & 95 & Yes \\
\hline $1-2$ August 2005 & & 88,93 & $105-120$ & \\
\hline 2-3 August 2005 & 95 & 90 & $105-120$ & No \\
\hline 3-4 August 2005 & 95 & 85,96 & 92,98 & Yes \\
\hline 4-5 August 2005 & & 96 & $96-98$ & \\
\hline 27-28 August 2005 & 95 & & $114-118$ & No \\
\hline 28-29 August 2005 & 95 & 93 & $96-100$ & Yes \\
\hline
\end{tabular}

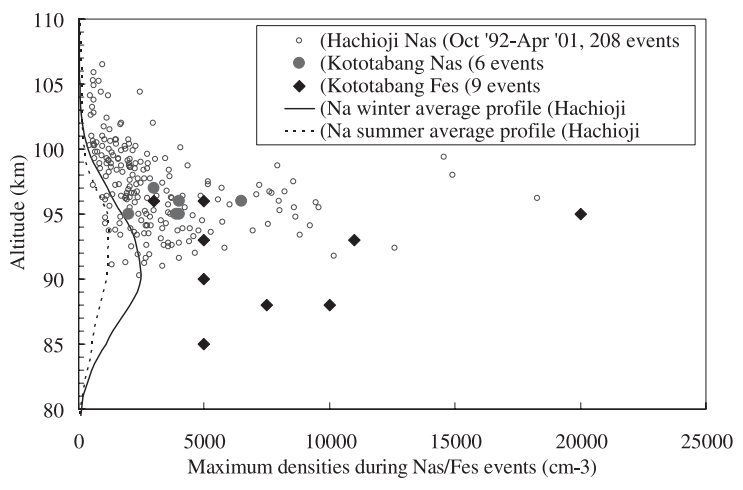

Fig. 6. Altitude distributions of Nas events and Fes events at Kototabang, Indonesia $\left(0^{\circ} \mathrm{S}\right)$ and $\mathrm{Nas}$ events at Hachioji, Japan $\left(35^{\circ} \mathrm{N}\right)$.

Nas in Japan (Hachioji and Shigaraki) to the normalized wind shear, i.e., the wind shear normalized as to the mean amplitude in each month, is shown in Fig. 7. The appearance of Nas or Fes is checked for every hour, and the event number will be counted if there is Nas or Fes. For example, since Nas shown in Fig. 3 is continued for four hours, the event number of Nas is 4 in all the night. The mean wind shear at Japan was $9.0 \mathrm{~m} / \mathrm{s} / \mathrm{km}$ and the mean window shear at Kototabang was $12.9 \mathrm{~m} / \mathrm{s} / \mathrm{km}$.

For the amplitudes of the wind shears at the peak altitude of Nas density, eleven of the 14 events exhibit wind shears exceeding the monthly mean, and five events exhibit shears

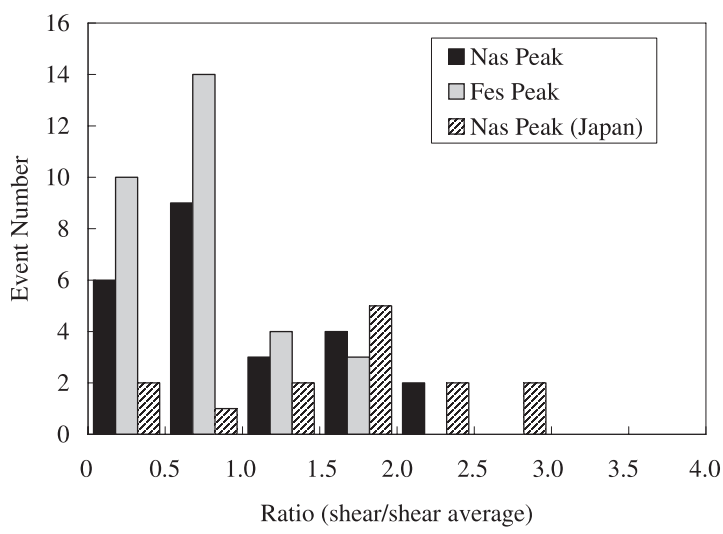

Fig. 7. Distributions of wind shears at the peak of Nas density and Fes density at Kototabang, and at the peak of Nas density at Hachioji and Shigaraki.

of more than twice the monthly mean at Hachioji and Shigataki. Shears were less than the monthly mean for only three events. Therefore, the wind shears around the time and altitude of Nas layers were significantly large in the midlatitude. The event number of the window share which divided total wind shear (ref. Fig. 7 ) into the zonal wind shear and the meridional wind shear are shown in Fig. 8. In Japan, there is no difference between the zonal wind shear and the meridional wind shear, and the event number of the wind shear does not have a peak. On the other hand, in Kototabang, the event number of the zonal wind shear is concentrated on the zero wind shear $(0 \mathrm{~m} / \mathrm{s} / \mathrm{km})$ 

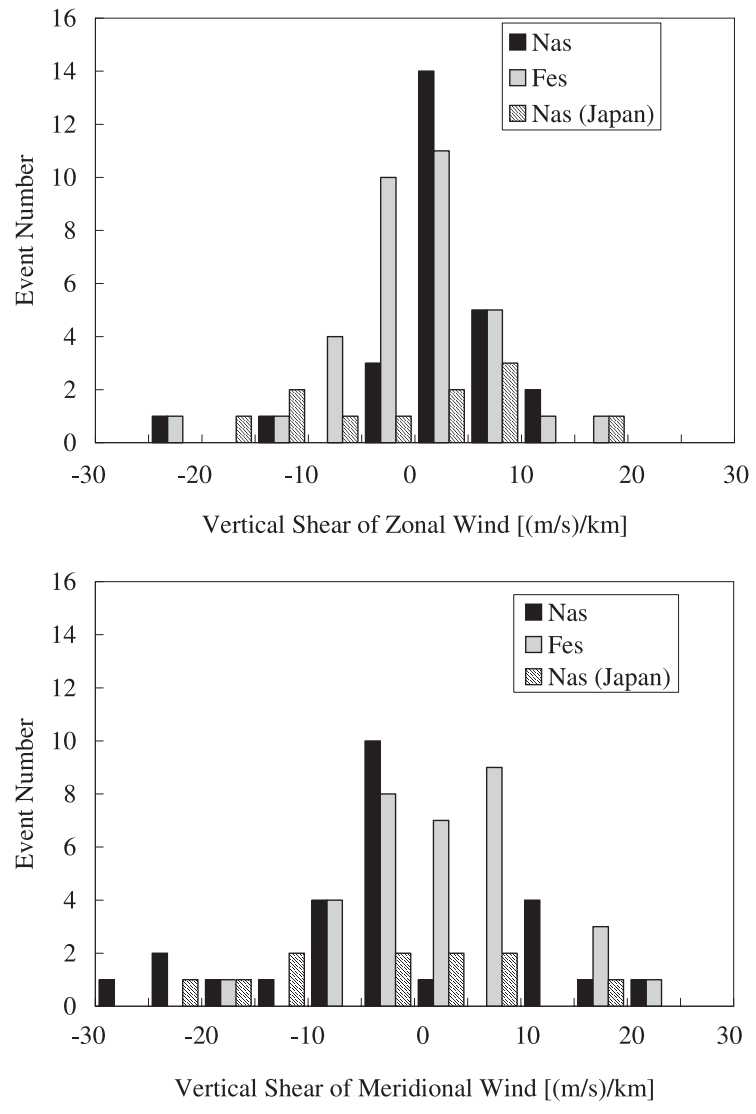

Fig. 8. Distributions of zonal and meridional wind shears at the peak of Nas density and Fes density at Kototabang, and at the peak of Nas density at Hachioji and Shigaraki (Japan).

compared with the event number of the meridional wind shear. Furthermore, the event number of Nas is concentrated on the zero wind shear compared with the event number of Fes. An Nas event accompanied with a strong wind shear observed by a $\mathrm{Na}$ wind/temperature lidar at Haleakala, Maui $\left(20.8^{\circ} \mathrm{N}, 156.2^{\circ} \mathrm{W}\right)$ was also reported (Gardner et al. 1995) and they observed a strong vertical shear of the zonal wind of $42 \mathrm{~m} / \mathrm{s} / \mathrm{km}$ at the altitude of $1 \mathrm{~km}$ below a prominent Nas layer. On the other hand, most zonal wind shears were less than $5.0 \mathrm{~m} / \mathrm{s} / \mathrm{km}$ at the peak altitude of Nas density and Fes density at Kototabang. The standard deviation of the zonal wind shear of Nas events is $7.3 \mathrm{~m} /$ $\mathrm{s} / \mathrm{km}$ and that of the meridional wind shear of Nas events is $12.3 \mathrm{~m} / \mathrm{s} / \mathrm{km}$. This result is completely opposite to the result of the mid-latitude and the wind shear does not contribute to pro- duction of Nas and Fes over the equator. This is an important discovery which indicates that the production process of Nas and Fes at the equator may be differ from the production process at the mid-latitude.

\section{Summary}

In this study, the correlations between the sporadic atomic layer (Nas and Fes) at equator area and dynamical parameters have been described by means of two resonance scattering lidars, the ionosonde and the meteor radar at Kototabang, Indonesia. Sporadic E layers and wind shears have been investigated at the times and heights of appearance of Nas layers and Fes layers, that were detected by the resonance scattering lidars.

First, we described the relation between Nas and Fes events and Es events. Nas events appeared only around $95 \mathrm{~km}$ at Kototabang. Nas and Fes events appear in the same time and height in many cases above $90 \mathrm{~km}$. However, only the Fes event appears below $90 \mathrm{~km}$ altitude. We showed that the Nas event and Es event were correlated. However the Fes event and Es event were not correlated. It is difficult to conclude the general relation among Nas, Fes and Es, because we have obtained several data in a limited period. We are continuing observations and it will be clarified from longterm data in the future.

Next, we described the relation between Nas and Fes events and the wind shear. Almost wind shears were less than the monthly mean at the peak altitude of Nas density and Fes density at Kototabang. It is shown that the Nas event is not influenced by the zonal wind. This result is completely opposite to the result of the mid-latitude. We consider that the production processes of Nas differ in the midlatitude and the equator. Temperature measurement in the mesopause and $\mathrm{Ca}$ ion layer measurement is required to clarify the generation mechanism of Nas.

\section{Acknowledgements}

CPEA campaign is financially supported by Grant-in-Aid for Scientific Research on Priority Area-764 of MEXT (Japanese Ministry of Education, Culture, Sports, Science and Technology). 


\section{References}

Beatty, T.J., R.L. Collins, C.S. Gardner, C.A. Hostetler, C.F. Sechrist, Jr., and C.A. Tepley, 1989: Simultaneous radar and lidar observations of sporadic E and $\mathrm{Na}$ layers at Arecibo. Geophys. Res. Lett., 16, 1019-1022.

Bills, R.E. and C.S. Gardner, 1990: Lidar observations of mesospheric $\mathrm{Fe}$ and sporadic Fe layers at Urbana, Illinois. Geophys. Res. Lett., 17(2), 143-146.

Bowman, M.R., A.J. Gibson, M.C.W. Sandford, 1969: Atmospheric Sodium measured by a tuned laser radar. Nature, 211, 456.

Chamberlain, J.W., D.M. Hunten, and J.E. Mack, 1958: Resonance scattering by atmospheric sodium. IV. Abundance of sodium in twilight. J. Atmos. Terr. Phys., 12, 153-165.

Clemesha, B.R., D.M. Simonich, and P.P. Batista, 1992: A Long-Term Trend in the Height of the Atmospheric Sodium Layer: Possible Evidence for Global Change. Geophys. Res. Lett., 19, 457-461.

, V.W.J.H. Kirchhoff, D.M. Simonich, and H. Takahashi, 1978: Evidence of an extraterrestrial source for the mesospheric sodium layer. Geophys. Res. Lett., 5(10), 873-876.

Felix, F., F.W. Keenliside, G. Kent, and M.C.W. Sandford, 1973: Laser Radar Observations of Atmospheric Potassium. Nature, 246, 345346.

Fukao, S., H. Hashiguchi, M. Yamamoto, T. Tsuda, T. Nakamura, M.K. Yamamoto, T. Sato, M. Hagio, and Y. Yabugaki, 2003: Equatorial atmosphere radar (EAR): System description and first results. Radio Sci., 38, 1053.

Gardner, C.S., D.G. Voelz, 1987: Lidar studies of the nighttime sodium layer over Urbana, Illinois, 2. Gravity waves. J. Geophys. Res., 92(A5), 4673-4694.

, D.C. Senft, and K.H. Kwon, 1988: Lidar observations of a substantial sodium depletion in the summertime Arctic mesosphere. Nature, 332, 142-144.

, X. Tao, and G.C. Papen, 1995: Observations of strong wind shears and temperature enhancement during several sporadic $\mathrm{Na}$ layer events above Haleakala. Geophys. Res. Lett., 22(20), 2809-2812.
Granier, C., J.P. Jegou, G. Megie, 1985: Resonant lidar detection of $\mathrm{Ca}$ and $\mathrm{Ca}^{+}$in the upper atmosphere. Geophys. Res. Lett., 12, 655-658. , J.P. Jegou, G. Megie, 1989: Iron atoms and metallic species in the Earth's upper atmosphere. Geophys. Res. Lett., 16, 243-246.

Hoffner, J., U. von Zahn, W.J. McNeil, and E. Murad, 1999: The 1996 Leonid shower as studied with a potassium lidar: Observations and inferred meteoroid sizes. J. Geophys. Res., 104A, 26332643.

Kwon, K.H., D.C. Senft, and C.S. Gardner, 1988: Lidar observations of sporadic sodium layers at Mauna Kea Observatory, Hawaii. J. Geophys. Res., 93, 14,199-14,208.

Megie, G., F. Bos, J.E. Blamont, and M.L. Chenin, 1978: Simultaneous nighttime lidar measurements of atmospheric sodium and potassium. Planet. Space. Sci., 26, 27-35.

Miyagawa, H., T. Nakamura, T. Tsuda, M. Abo, C. Nagasawa, T.D. Kawahara, K. Kobayashi, T. Kitahara, and A. Nomura, 1999: Observations of mesospheric sporadic sodium layers with the MU radar and sodium lidars. Earth Planets Space, 51, 785-797.

Nagasawa, C. and M. Abo, 1995: Lidar observations of a lot of sporadic sodium layers in midlatitude. Geophys. Res. Lett., 22(3), 263-266.

Nomura, A., T. Kano, Y. Iwasaka, H. Fukunishi, T. Hirasawa, and S. Kawaguchi, 1987: Lidar observations of the mesospheric sodium layer at Syowastation, Antarctica. Geophys. Res. Lett., 14, 700-703.

von Zahn, U., P. von der Gathen, and G. Hansen, 1987: Forced release of sodium from upper atmospheric dust particles. Geophys. Res. Lett., 14, 76-79.

and T.L. Hansen, 1988: Sudden neutral sodium layers: a strong link to sporadic E layers. J. Atmos. Terr. Phys., 50, 93-104.

Zhou, Q., J.D. Mathews, and C.A. Tepley, 1993: A proposed temperature dependent mechanism for the formation of sporadic sodium layers. $J$. Atmos. Terr. Phys., 55(3), 513-521.

Plane, J.M.C., R.M. Cox, J. Qian, W.M. Pfenninger, G.C. Papen, C.S. Gardner, and P.J. Espy, 1998: Mesospheric $\mathrm{Na}$ layer at extreme high latitudes in summer. J. Geophys. Res., 103, 63816390 . 